\title{
An unusual manifestation of amyloidosis in lungs
}

\author{
Sarina Nikzad ${ }^{1}$, Amna Al-Arnawoot ${ }^{1}$, Patrik Rogalla ${ }^{1}$, and Michael Cabanero ${ }^{1}$ \\ ${ }^{1}$ University Health Network
}

November 6, 2020

\begin{abstract}
Nodular pulmonary amyloidosis is a rare and localized manifestation of amyloid deposition in the lungs. This rare entity, though asymptomatic, is often misdiagnosed on imaging alone, due to its resemblance to metastatic pulmonary nodules. This report highlights the significance of histologic confirmation before treatment, as a preventive measure against overtreatment.
\end{abstract}

\section{Hosted file}

wiley-casereport .pdf available at https://authorea.com/users/373582/articles/491240-anunusual-manifestation-of-amyloidosis-in-lungs
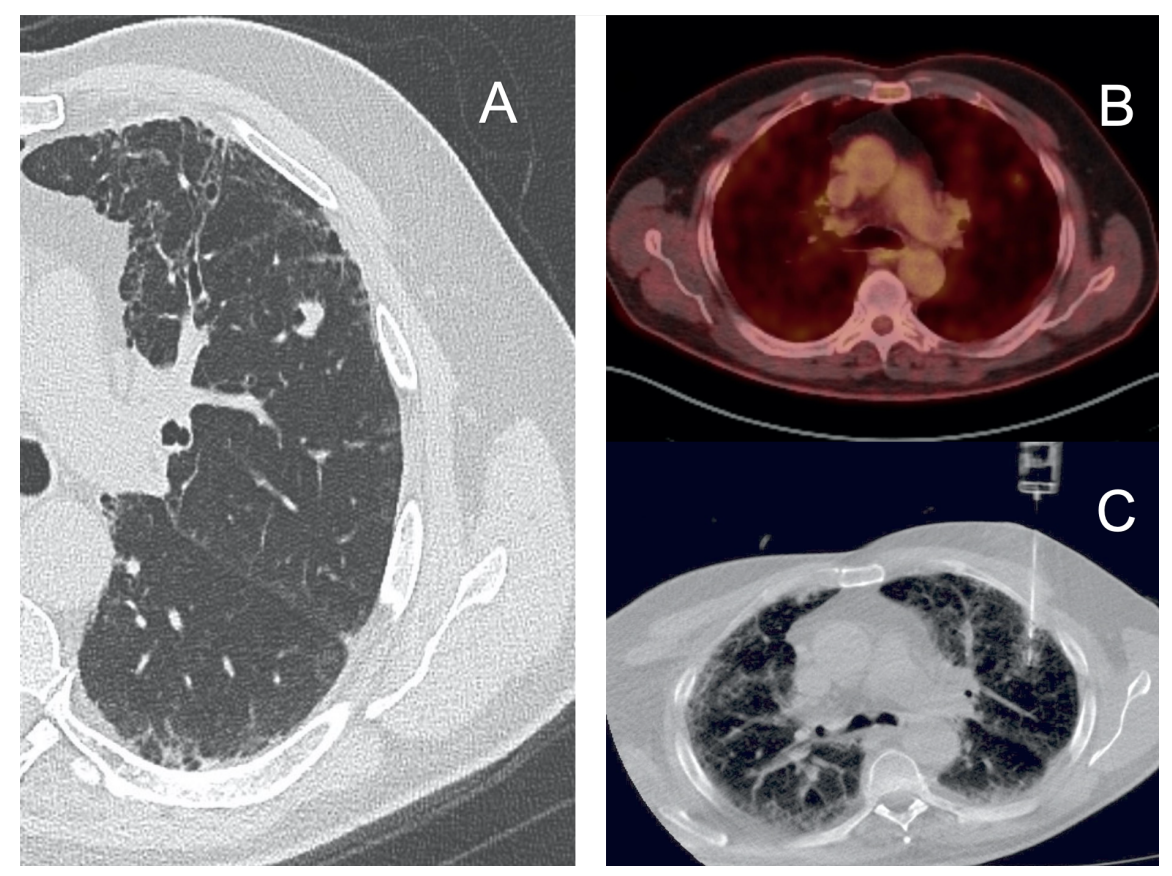


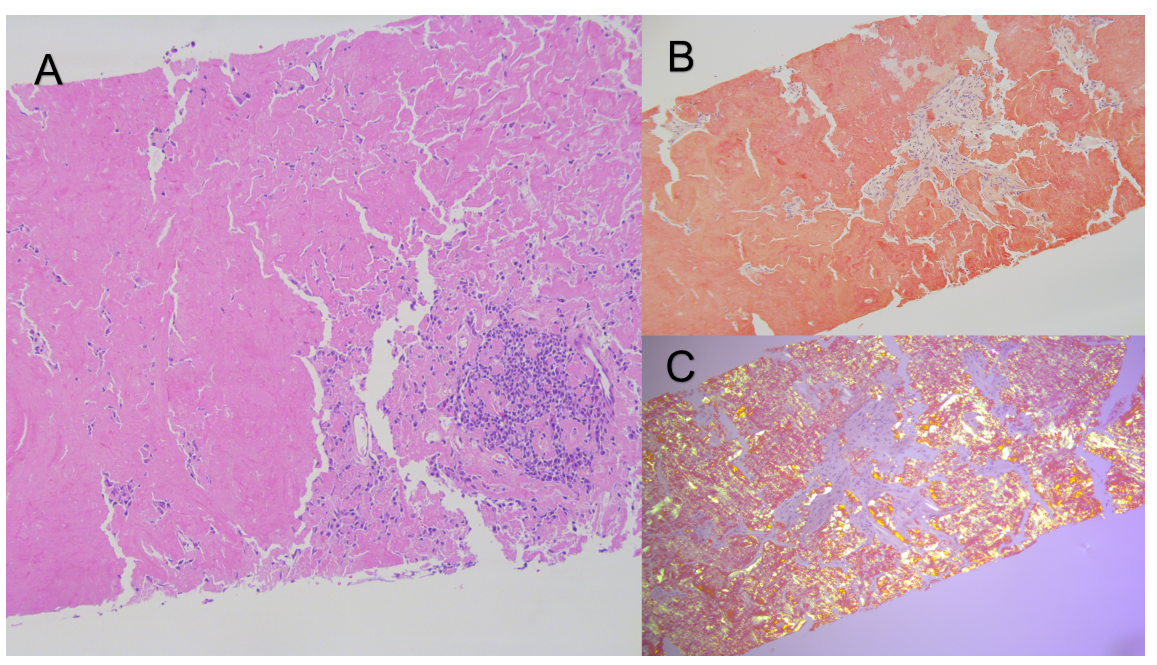

